\title{
Por uma Terminografia Pedagógica
}

DOl: http://dx.doi.org/10.21165/el.v49i2.2637

\section{Guilherme Fromm ${ }^{1}$}

\section{Resumo}

O objetivo deste trabalho é, em primeiro lugar, apresentar o campo da Terminografia Pedagógica, mostrando suas possíveis bases teóricas e metodológicas, a importância da Linguística de Corpus neste tipo de trabalho, além de alguns exemplos de pesquisa advindos de um ambiente de gerenciamento terminográfico e sua respectiva página de visualização. Como resultado, apresento minha proposta para o que considero elementos fundamentais para o desenvolvimento e consecução de uma Terminografia Pedagógica.

Palavras-chave: terminografia pedagógica; linguística de corpus; aprendizagem; ambiente de gerenciamento terminográfico.

1 Universidade Federal de Uberlândia (UFU), Uberlândia, Minas Gerais, Brasil; guifromm@ufu.br; https://orcid.org/0000-0001-5654-0135 


\title{
Towards a Pedagogical Terminography
}

\begin{abstract}
The aim of this paper is, firstly, to present the field of Pedagogical Terminography, showing its possible theoretical and methodological approaches and the importance of Corpus Linguistics in this kind of work, besides some research examples coming from a corpus management environment and its respective visualization page. As a result, I present my proposal for what I consider fundamental elements for the development and achievement of a Pedagogical Terminography.
\end{abstract}

Keywords: pedagogical terminography; corpus linguistics; learning; terminographic management environment.

\section{Apresentação}

Estudos sobre o Léxico, juntamente com sua Morfologia e Etimologia, são uma constante desde os primórdios da herança linguística ocidental. Podemos dizer que as palavras são os tijolos que fazem parte da construção de uma determinada língua; por esta razão, estudos nessa área sempre existirão, dada a dinamicidade das mudanças lexicais. Numa proposta linguística brasileira mais moderna (a partir de OLIVEIRA; ISQUERDO, 2001 e livros subsequentes dentro da coleção), a área dos estudos lexicais vem sendo dividida entre três grandes subáreas: Lexicologia, Lexicografia e Terminologia. Dentro de cada uma delas, encontramos mais subdivisões (Onomástica, Terminografia) e abordagens. Apresento, neste artigo, algumas bases e propostas para uma abordagem na subárea de Terminografia: a Terminografia Pedagógica² (em analogia à abordagem da Lexicografia Pedagógica, dentro da Lexicografia). Este artigo está dividido em cinco seções: nesta primeira, faço uma pequena introdução à área do Léxico; na segunda, apresento alguns referenciais teóricos que servem de sustentação para a abordagem e para as propostas apresentadas; a metodologia a ser trabalhada é apresentada na terceira seção; na quarta, apresento a proposta de um projeto que pode ser desenvolvido em um curso superior e, na quinta, teço minhas considerações finais.

\section{Referenciais teóricos}

A grande área do Léxico, em termos práticos, pode ser dividida em duas grandes vertentes: a teórica (-logia) e a prática (-grafia). Minha proposta parte de divisões e subdivisões já existentes e consolidadas, através de vários estudos na vertente de prática dos estudos lexicais. Para situar melhor essa proposta de prática, preciso, em primeiro lugar, fornecer as bases teóricas que a sustentam.

2 Barbosa (2009) já previu algumas das questões levantadas aqui, mas sua denominação para toda uma proposta de ensino de Terminologia foi denominada Terminodidática. 
Em primeiro lugar, é importante citar um panorama genérico de como essas áreas estão divididas. A Lexicologia tem como foco o estudo do Léxico, de um modo geral, e do léxico de uma determinada língua, como objeto específico. Segundo Zavaglia e Welker (2008), a Lexicologia se detém nas palavras e cada uma delas "remete a particularidades relacionadas ao período histórico em que ocorre, à região geográfica a que pertence, à sua realização fonética, aos morfemas que a compõem, à sua distribuição sintagmática, ao seu uso social e cultural, político e institucional". A Lexicografia, com viés prático, se propõe a "elaborar obras de referência, principalmente dicionários, impressos ou on-line, além de bases de dados lexicais" (ZAVAGLIA; WELKER, 2008) e pode ser subdividida entre o estudo sobre como elaborar uma obra lexicográfica (a Metalexicografia) e a elaboração da obra em si (Lexicografia Prática).

Enquanto a Lexicologia e a Lexicografia se atêm ao léxico de uma língua como um todo, a Terminologia já trabalha com um recorte específico dessa, o "conjunto vocabular próprio de uma ciência, técnica, arte ou atividade profissional" (ALMEIDA; CORREIA, 2008). Espelhada nas duas primeiras, a Terminologia pode ser dividida entre o estudo teórico sobre uma determinada área de conhecimento (a terminologia da computação, por exemplo) e o estudo prático sobre essa área, a Terminografia, que também se divide entre os questionamentos de como elaborar uma obra terminográfica (a Metaterminografia) e a própria elaboração da mesma (Terminografia Prática).

Pensando em abordagens com as quais podemos trabalhar dentro de cada linha, destaco a Lexicografia Pedagógica (como abordagem da Lexicografia), que já é uma realidade nos estudos e elaboração de dicionários voltados para públicos específicos (notadamente aprendizes de línguas materna e estrangeira) e que começa a ser trabalhada, no Brasil, a partir do século XXI (DARÉ-VARGAS, 2018). Essa abordagem trabalha tanto a parte teórica (estudos sobre dicionários pedagógicos; também conhecida como Metalexicografia Pedagógica), quanto a prática do fazer lexicográfico (elaboração de dicionários pedagógicos) ${ }^{3}$.

Tendo em vista todas essas possíveis subdivisões dos estudos lexicais, sigo, de acordo com o Quadro 1, um sistema proposto por Barbosa (2001), no qual a autora classifica a tipologia de possíveis obras baseadas no léxico de uma língua. Dentro da proposta do presente artigo, trabalho com as ideias de vocabulário (denominação do tipo de obra), vocábulo (recorte de língua usado por determinado grupo social) e termo (pertencente a uma área de especialidade).

30 PNLD (2012), por exemplo, dividiu os dicionários escolares em quatro categorias e os dicionários existentes no mercado foram encaixados (se apresentassem pertinência) numa dessas quatro categorias. 
Quadro 1. Obras lexicais, segundo os níveis de atualização na língua

\begin{tabular}{|c|c|c|}
\hline Dicionário & Vocabulário & Glossário \\
\hline Nível do sistema & Nível da norma & Nível da fala \\
\hline $\begin{array}{c}\text { Trabalha com todo o léxico } \\
\text { disponível e o léxico virtual }\end{array}$ & $\begin{array}{c}\text { Trabalha com conjuntos } \\
\text { manifestados dentro de uma } \\
\text { área de especialidade }\end{array}$ & $\begin{array}{c}\text { Trabalha com conjuntos } \\
\text { manifestados em um } \\
\text { determinado texto }\end{array}$ \\
\hline $\begin{array}{c}\text { Unidade: lexema (significado } \\
\text { abrangente; frequência } \\
\text { regular) }\end{array}$ & $\begin{array}{c}\text { Unidade: vocábulos/termos } \\
\text { (significado restrito; alta } \\
\text { frequência) }\end{array}$ & $\begin{array}{c}\text { Unidade: palavras } \\
\text { (significado específico; única } \\
\text { aparição) }\end{array}$ \\
\hline $\begin{array}{c}\text { Apresenta (teoricamente) } \\
\text { todas as acepções de um } \\
\text { mesmo verbete }\end{array}$ & $\begin{array}{c}\text { Apresenta todas as acepções } \\
\text { de um verbete dentro de uma } \\
\text { área de especialidade }\end{array}$ & $\begin{array}{c}\text { Apresenta uma única } \\
\text { acepção do verbete } \\
\text { (dentro de um contexto } \\
\text { determinado) }\end{array}$ \\
\hline $\begin{array}{c}\text { Perspectivas: diacrônica, } \\
\text { diatópica, diafásica e } \\
\text { diastrática }\end{array}$ & Perspectivas: sincrônica e \\
sinfásica & $\begin{array}{c}\text { Perspectivas: sincrônica, } \\
\text { sintópica, sinstrática e } \\
\text { sinfásica }\end{array}$ \\
\hline
\end{tabular}

Fonte: Sistematizado a partir das teorias de Barbosa (FROMM, 2002)

Para estudos na área de Terminologia, dispomos de várias teorias (Teoria Geral da Terminologia, Teoria Comunicativa da Terminologia, Socioterminologia, Teoria Sociocognitiva da Terminologia, Terminologia Textual, Terminologia Cultural, Etnoterminologia), como bem apresentado por Carneiro (2016). No presente estudo, duas delas servem de base para minhas propostas: a Teoria Comunicativa da Terminologia (TCT), de Cabré (2000), e a Etnoterminologia, de Barbosa (2006).

Cabré (2000) propõe doze pressupostos para a sua teoria de caráter eminentemente descritivo, dos quais destaco (para fins deste trabalho): o termo é uma associação entre conteúdo (traços percebidos a partir de uma estrutura conceitual num contexto especializado) e forma (uma definição linguística a partir do conteúdo); um termo apresenta uma dupla sistematicidade em relação à língua e à área de especialidade a qual pertence; a elaboração de um termo parte de textos (escritos ou orais) reais de uma área de especialidade; a categoria gramatical dos termos é, basicamente, os substantivos; um trabalho terminológico conduz sempre a uma aplicação (como um vocabulário). Em relação à metodologia, é importante destacar que a autora reconhece que "com exceção de seus princípios mínimos que lhe servem como marco, cada trabalho concreto adota uma estratégia em função de sua temática, objetivos, contexto, elementos implicados e 
recursos disponíveis" (CABRÉ, 2000, p. 137, tradução nossa4). A autora pressupõe, ainda, uma concepção menos hierárquica e menos segmentada do conhecimento (proposta na Teoria Geral da Terminologia, de Wüster, de caráter prescritivo e que buscava a univocidade na comunicação especializada), voltada para a comunicação natural, de base social, e assume que o termo pode transitar entre a linguagem comum e âmbitos especializados; nesse caso, uma lexia (ou fraseologia) geral da língua está termo dentro de uma determinada área, não significando que ela exista apenas como termo e, ao mesmo tempo, concatena-se a possibilidade de que essa lexia ou esse termo estejam sujeitos às diferentes concepções de mundo por parte da língua a que pertencem, ligando-se a traços semânticos e pragmáticos de acordo com a situação comunicativa.

Em consonância com essa proposta comunicativa de Cabré, Barbosa (2006) propõe uma possibilidade de análise mais específica, a qual denominou de Etnoterminologia. Assim como na TCT, o termo está termo, mas, desta vez, dentro de um discurso narrativo ou literário. Barbosa pressupõe que existe um movimento de terminologização de unidades lexicais (passando de vocábulos para termos), e também que (voltando ao Quadro 1) essas unidades podem assumir uma dupla função: vocábulo (pensado como um recorte do léxico geral, usado por determinado grupo de falantes e representando seu universo de discurso) e termo (dentro de uma linguagem quase de especialidade), o que nos leva de volta ao sistema da língua e tudo o que ele representa, resultado naquilo que denomino, aqui, como etnotermo ${ }^{5}$. Em sua proposta Barbosa coloca que o mesmo é construído dentro da narrativa de uma obra literária, não obedecendo, necessariamente, aos conceitos da língua comum ou de especialidade; para entender o significado específico desse etnotermo, temos que ter ciência (e aprender) de como a história funciona e como interpretá-lo no formato de termo dentro da narrativa.

Para a consecução de trabalhos lexicográficos e terminográficos, na atualidade, a abordagem e a metodologia da Linguística de Corpus (LC) passam a ser as mais adotadas; elas são de base empírica e pressupõem, como já apontado por Cabré (1999), uma análise de textos (sempre compilados com uma perspectiva de balanceamento entre os conteúdos) relativos às áreas pesquisadas. Berber Sardinha (2004) pressupõe que a LC só pode ser realizada com o auxílio de computadores. Mais especificamente, Tagnin (2004) observa que se trata de "uma coletânea de textos em formato eletrônico, compilada segundo critérios específicos, considerada representativa de uma língua (ou da parte que se pretende estudar), destinada à pesquisa", além de destacar (2010) que os estudos relacionados à LC podem ser baseados em corpora (o corpus é usado para

4 No original: "Con excepción de los principios mínimos que le sirven de marco, cada trabajo em concreto adopta una estrategia em función de su temática, objetivos, contexto, elementos implicados y recursos disponibles".

50 próprio termo já existe, mas dentro de uma perspectiva da Etnografia e da Ecolinguística, com um viés teórico e significado diferentes. Por extensão, podemos entender, também, a existência de etno-fraseologismos. 
comprovar (ou não) uma hipótese ou para extrair exemplos) ou direcionado pelos corpora (o estudo se desenvolve conforme dados apresentados pelo corpus, sem pressuposições teóricas). Teixeira (2008), baseada em Berber Sardinha (2004), aponta as possíveis tipologias na construção de um corpus de pesquisa: língua (monolíngue ou plurilíngue), modo (escrito ou oral), período de seleção (sincrônico ou diacrônico), seleção (estático ou monitor), conteúdo (especializado ou geral de língua), autoria (falantes nativos ou não-nativos, individual ou coletivo), disposição interna (comparável ou paralelo), uso na pesquisa (estudo ou referência), tamanho e nível de codificação (cabeçalhos, etiquetas). O projeto de um corpus, na área de Terminografia, também pressuporia a elaboração de uma Árvore de Domínio (KRIEGER; FINATO, 2004, p. 134), a fim de se alcançar um balanceamento de textos entre as diversas subáreas de uma grande área, além de servir como mapa para a elaboração de conceitos dá área estudada. Existem dezenas de áreas especializadas nas tentativas de elaboração de uma grande taxonomia da ciência (como na "Tabela de Áreas do Conhecimento", do $\mathrm{CNPq}^{6}$ ); neste trabalho, tento mesclar algumas áreas de conhecimento existentes nessas taxonomias com os pressupostos da TCT e da Etnoterminologia, e lido com textos literários, ao invés de científicos (como artigos, dissertações, teses, documentos de divulgação científica).

Proponho uma releitura, dentro da Etnoterminologia, do que seja um texto literário: aqui estendo sua proposta para seriados de televisão (FROMM, 2011). Com o surgimento da televisão, seguida pela estreia de seriados, considero que esses (em seu todo) possam ser tomados como universos literários que passam a se preocupar, no avançar dos anos, com um elemento básico nos estudos sobre literatura: a verossimilhança ${ }^{7}$. Para atingir seu público-alvo por várias temporadas (alguns seriados passam de vinte), é necessário haver uma coerência interna em como os fatos são apresentados; além disso, vários seriados apresentam elementos que remetem às terminologias reais de diversas áreas do conhecimento descritas nas grandes taxonomias da ciência. Proponho uma tipologia8 de três tipos para seriados que contenham terminologias: a. Profissão (procedimental): retrata o cotidiano de médicos, investigadores, cientistas forenses e profissionais das mais diversas áreas, apresentando terminologias que tentam retratar, de forma fiel, aquelas usadas pelos profissionais dessas áreas nos seus afazeres cotidianos; b. Ficçãocientífica (procedimental ou serializada): misturam ficção e ciência, característica básica da área literária, fílmica e televisiva de ficção científica; nesses programas encontramos terminologia própria de áreas reais como Física, Química, Astronáutica, Astronomia, Engenharias, Biologia, etc.; no entanto, como a ficção também se faz presente, termos

6 Disponível em: https://bit.ly/3fjAfpm. Acesso em: 14 set. 2019.

7 "ligação, nexo ou harmonia entre fatos, ideias etc. numa obra literária, ainda que os elementos imaginosos ou fantásticos sejam determinantes no texto; coerência" (HOUAISS, 2009, grifos meus).

8 Precedida por uma tipologia básica, que divide as séries entre procedimentais (têm começo, meio e fim dentro de um mesmo episódio, ou seja, a trama se resolve em 40/50 minutos) e serializadas (uma história pode ser desenvolvida por toda uma temporada, ou até por toda a série). 
são criados, dentro dessas áreas, para explicar fenômenos que ainda não podem ser explicados ou, também, fenômenos inventados; c. Ficção (procedimental ou serializada): elas apresentam uma terminologia totalmente ficcional, exibem temáticas sobre 0 fantástico, com personagens e características que existem apenas em mundos criados a partir da imaginação; podem, também, retratar o folclore de diversos povos e, em virtude disso, apresentar um mesmo etnotermo (como Lobisomem) com diversas acepções (o que a TCT também já propõe) de uma série para outra.

Projetos relacionados ao ensino de Terminologia e/ou Terminografia não são novidade. Eles apresentam vários tipos de estudos e destaco alguns: projetos de interação entre ensino médio e superior com a proposição de melhorar definições para um público-alvo específico (LAFACE, 2001); estudos sobre maneiras de estabelecer um vínculo entre termos técnico-científicos e vocábulos da linguagem banalizada para que o aprendiz tenha acesso às áreas técnicas (BARBOSA, 2004); projeto de educação linguística (no sentido de divulgar que Linguista também pode ser uma profissão que o aluno vá escolher no futuro) para crianças no ensino fundamental II, propondo, entre vários temas, o reconhecimento da existência de terminologias que as crianças já reconhecem e exercícios para aprendizado de novas terminologias (CABRÉ; ESTOPÀ; FREIXA, 2006); descrição na elaboração de um dicionário (vocabulário, seguindo a proposta apresentada abaixo no quadro 1) na área de Linguística da Enunciação voltado para um público-alvo específico, a saber, alunos nos semestres finais de uma graduação ou alunos de pósgraduação (FINATTO, 2010). Cada um desses estudos aborda, de alguma maneira, características que trabalho neste texto.

Tendo levantado todas essas questões teóricas, parto agora para os procedimentos metodológicos adotados no projeto Terminologia em Fiç̧ão (TF).

\section{Passos metodológicos}

O projeto Terminologia em Ficção (TF) tenta resgatar, em parte, princípios da Lexicografia Pedagógica, que pressupõem o recorte de um léxico geral de determinada língua para públicos-alvo de aprendizes dessa língua. De acordo com as especificidades de cada público-alvo, o conteúdo de um dicionário (tanto na macro- quanto nas microestruturas) muda; o que a maioria dos textos da área propõe, no entanto, é apenas como elaborar ou melhorar (na forma de crítica) essas obras de referência. O projeto TF pretende uma dupla função: que o público-alvo aprenda a elaborar uma obra terminográfica e que a mesma, concomitantemente, se adeque a esse público-alvo.

A escolha de seriados de televisão, obviamente, não foi aleatória. O público-alvo escolhido foram estudantes universitários (na graduação, na iniciação científıca ena pós-graduação). Percebi, desde o começo de minha carreira universitária, que discussões entre alunos sobre seriados de televisão (assim como telenovelas) nunca saem de moda. Por que não capitalizar, então, esse interesse nos seriados para um trabalho de aprendizado? 
Obviamente que muitos seriados de interesse do público-alvo não se encaixavam na tipologia apresentada no item anterior visando trabalhos etnoterminológicos. Percebi, logo no começo da empreitada, que a mão do professor é essencial para guiar os alunos na escolha de um seriado que possa ser trabalhado nesse viés.

O primeiro passo na metodologia, portanto, é a escolha do seriado a ser trabalhado, escolha essa feita de comum acordo entre o(s) aluno(s) e o professor; como já existe um ambiente de gestão terminográfico de cunho bilíngue (português/inglês bidirecional) desenvolvido a partir de outro trabalho (FROMM, 2007), normalmente os alunos trabalham em duplas, cada um cuidando de uma língua ${ }^{9}$. O segundo passo é a compilação do corpus do seriado escolhido nas duas línguas ${ }^{10}$ através das legendas ${ }^{11}$ desses seriados, o que é feito de maneira bastante rápida. Escolher qual programa de análise lexical a ser usado se constitui o terceiro passo; dependendo do nível de conhecimento de informática dos alunos, podemos optar entre uma suíte de análise lexical executável, como o AntConc ${ }^{12}$, uma suíte instalável no computador, como o WordSmith Tools ${ }^{13}$ ou um ambiente online de gerenciamento e análise de corpora, como o Sketch Engine ${ }^{14}$; todas as opções anteriores apresentam vantagens (como gratuidade ou fácil acesso) ou desvantagens (como a não gratuidade ou a não possibilidade de salvar o trabalho de análise). Seja qual for a opção informatizada usada no terceiro passo, o aluno trabalhará com três ferramentas básicas para a Linguística de Corpus: lista de palavras (contendo todas as palavras distintas do corpus, suas frequências de uso, etc.), palavras-chave (listagem elaborada a partir da análise contrastiva com outro corpus, no mínimo cinco vezes maior, denominado como corpus de referência; a listagem apresentada como resultado indica prováveis candidatos a etnotermos no corpus de estudo) e linhas de concordância (onde se demonstra, numa sucessão de linhas e com o termo escolhido centralizado, como se

9 Mesmo trabalhando línguas separadas, os alunos devem tomar decisões conjuntas. Toda essa fase é desenvolvida em um laboratório de informática e os pares trabalham em computadores lado a lado, discutindo sobre as decisões a serem tomadas.

10 Desde o advento do compartilhamento de dados através do sistema de torrents e dos sites de streaming (como o YouTube, o Netflix, o Prime Video e outros), o acesso às legendas de seriados é bastante simples: elas podem ser baixadas de sites especializados (como o www.legendas.tv ou www.opensubtitles.org) ou extraídas (através de softwares especializados) dos sites de streaming.

11 As legendas, em inglês, normalmente são uma reprodução do sistema closed caption, enquanto as em português são traduções das mesmas. A composição do corpus se configura, portanto, como paralela, com textos originais e suas respectivas traduções.

12 Disponível em: https://www.laurenceanthony.net/software/antconc/

13 Disponível em: https://lexically.net/wordsmith/index.html

14 Disponível em: https://www.sketchengine.eu/. Para visualizar um quadro comparativo entre o WordSmith Tools e o Sketch Engine, acesse: http://dx.doi.org/10.17851/2237-2083.28.3.1191-1248 
comportam as coligações, colocações e clusters, numa perspectiva fraseológica ${ }^{15}$, deste possível etnotermo).

Tendo escolhido, no terceiro passo, as palavras-chave (e também fraseologismos) e de posse de suas linhas de concordância, os alunos podem caminhar para o quarto passo, que é o tratamento dessas informações previamente levantadas através de uma ferramenta que Wilkens et al. (2012) denominaram ambiente web de gestão terminológica para a criação de produtos terminológicos on-line, no nosso caso, o VoTec (FROMM, 2007). 0 professor inicia um projeto (com o nome do seriado escolhido), os alunos se inscrevem no ambiente e iniciam a produção de cinco verbetes bilíngues (no par português/ inglês bidirecional) relacionados a esse seriado. O VoTec pressupõe, desde sua fase de desenvolvimento, o trabalho com linhas de concordância, ou seja, é um ambiente baseado em corpus e se divide em dois grandes blocos: um banco de dados (com o qual os alunos trabalham para inserir os mais diversos tipos de informação) e uma página de visualização dos resultados (disponível em: http://ic.votec.ileel.ufu.br). Os passos a serem trabalhados no banco de dados são os seguintes (do passo b em diante, toda a informação a ser inserida deve vir das linhas de concordância): a. inserção das linhas de concordância do etnotermo escolhido; b. preenchimento dos dados morfossintáticos do etnotermo/etnofraseologismo; c. preenchimento das informações advindas do corpus (como frequência); d elaboração dos traços distintivos do etnotermo/etnofraseologismo, baseado na proposta de Análise Componencial de Ilari (2003); e. levantamento, através das linhas de concordância, das relações semânticas que o etnotermo/etnofraseologismo apresenta nos textos: sinonímia, antonímia, hiponímia, hiperonímia, co-hiponímia; f. ligação do etnotermo/etnofraseologismo com o seu equivalente na outra língua ${ }^{16}$; g. verificação se já há algum etnotermo/etnofraseologismo cadastrado que possa funcionar como remissivo; $\mathbf{h}$. fornecimento de informações enciclopédicas sobre o etnotermo/etnofraseologismo 17; i. elaboração de um primeiro protótipo de definição; j. elaboração da definição final do etnotermo/etnofraseologismo, que será disponibilizada na página de visualização. O último passo no ambiente é dado pelo gestor do projeto (normalmente o professor), que aprova, reprova ou pede correção dos verbetes criados. Após aprovação, os dados estão disponíveis para todo o público, como podemos verificar na próxima seção deste trabalho.

15 Existem várias noções do que seja um fraseologismo, mas considero o mesmo, neste texto, como qualquer agrupamento de duas ou mais palavras cuja frequência combinada seja destacada pelos programas de análise lexical.

160 que só pode ser feito quando o termo/fraseologismo já está cadastrado em uma língua. Nos trabalhos em pares, um aluno tem que esperar o colega terminar o termo/fraseologismo em questão para que possa ligá-lo.

17 Como as informações desta seção serão apresentadas ao público, solicito aos alunos que usem fontes sem reservas de direito autoral, como a Wikipédia. 


\section{Resultados}

Qualquer consulente pode acessar a página de visualização, onde encontrará os projetos (14 cadastrados no momento) e seus respectivos verbetes. A página de visualização permite vários formatos de acesso ao verbete ${ }^{18}$. Nas figuras 1, 2 e 3 podemos ver 0 resultado de três verbetes, seguindo a proposta de seriados de televisão apresentada na seção 2 deste texto. No caso da figura 1, o seriado sobre profissão trabalhado foi House e o trabalho foi elaborado por uma só aluna ${ }^{19}$ (que trabalhou com as duas línguas).

Figura 1. Verbete tomografia/scan

\begin{tabular}{|c|c|}
\hline \multirow{3}{*}{$\begin{array}{l}\text { Tipos de Exibição } \\
\text { Normal } \\
\text { Descritiva }\end{array}$} & $\boldsymbol{\nabla}$ Português \\
\hline & \multirow{3}{*}{$\begin{array}{l}\text { Voltar ao resultado da busca } \\
\text { Tomografia. House. Tomografia. s.f.s. exame feito para diagnosticar doenças, tais como tumores, epilepsia, } \\
\text { cistos, vasculite do SNC, e que não pode ser feito em pacientes que possuem titânio e/ou objetos de metal } \\
\text { no corpo. Ex.: Faça uma tomografia da árvore biliar para descartar cálculos.. Córpus: Posição na Ordem de } \\
\text { Freqüência: }(96) ; N^{\circ} \text { de Ocorrências do termo: }(180) \text {. Informações Enciclopédicas: É uma técnica assistida } \\
\text { por computador, em que dados de diferentes perfis são combinados e calculados para formar imagens "em } \\
\text { fatias" dos objetos analisados, sendo comum o seu uso, atualmente, em medicina. Em: Tomografia - } \\
\text { Wikipedia }\end{array}$} \\
\hline & \\
\hline $\begin{array}{l}\text { Tipos de Consulta } \\
\text { Total } \\
\text { Tradutor } \\
\text { Modular }\end{array}$ & \\
\hline \multirow{4}{*}{$\begin{array}{l}\text { Consultas Externas } \\
\text { Corpus NILC } \\
\text { Google } \\
\text { Answers.com } \\
\text { Wikipedia } \\
\text { CORTEC }\end{array}$} & \\
\hline & $\boldsymbol{\nabla}$ English \\
\hline & Go back to search results \\
\hline & $\begin{array}{l}\text { Scan. House. } \mathrm{n} \text {.m/f.s. an exam that can be done to reveal pituitary damage, pulmonary aneurysm and biliary } \\
\text { tumor, among other things. It can also reveal if there has been any changing metabolic activity in the } \\
\text { cerebral cortex, ischemia or death of brain tissue, and can be used to locate a bleed. Ex.: "The base of the } \\
\text { brain, leading to a pituitary adenoma, which leaks GNRH. Pituitary damage would not be visible on a CT } \\
\text { scan.". Corpus: Frequency order position: (73); Term number of occurrencies: (159). Encyclopedic } \\
\text { Information: A picture of structures inside the body. Scans often used in diagnosing, staging, and monitoring } \\
\text { disease include liver scans, bone scans, and computed tomography (CT) or computerized axial tomography } \\
\text { (CAT) scans and magnetic resonance imaging (MRI) scans. em: Scan - Encyclo - Online Encyclopedia }\end{array}$ \\
\hline
\end{tabular}

\section{Fonte: Elaborado por Mila Bang}

No caso da figura 2, temos um etnofraseologismo advindo de uma série de ficção científica, Jornada nas Estrelas. Esse etnofraseologismo é inventado na série, mas usa outro fraseologismo próprio da Astronomia para explicar sua elaboração: a velocidade da luz.

180 projeto original deste autor prevê três modelos de visualização: um tradicional (compacto ou estendido), um criado para tradutores e um no qual o consulente escolhe que campos da microestrutura do verbete quer visualizar, criando uma experiência pessoal.

19 Importante notar que o sistema dá crédito de elaboração do verbete ao(s) aluno(s), como pode ser visto no canto inferior direito da figura. 
Figura 2. Verbete velocidade de dobra/warp speed

\begin{tabular}{|c|c|}
\hline \multirow{3}{*}{$\begin{array}{l}\text { Tipos de Exibição } \\
\text { Normal } \\
\text { Descritiva }\end{array}$} & $\nabla$ Português \\
\hline & \multirow{4}{*}{$\begin{array}{l}\text { Voltar ao resultado da busca } \\
\text { Velocidade de Dobra. Jornada nas Estrelas. s.f.s. A rapidez com que uma espaçonave se desloca pelo } \\
\text { espaço, medida conforme um fator de dobra. O fator } 1 \text { é igual à velocidade da luz. Valores menores do que } 1 \\
\text { indicam velocidade sub luz. A partir do fator } 1 \text {, uma espaçonave se desloca a velocidades cada vez mais } \\
\text { rápidas que a luz, conforme suas próprias capacidades de dobra.. Ex.: - Estou captando uma grave distorção } \\
\text { subespacial, senhor. Se expande para nós. Parece interferir com nossos reatores, Capitão. Não posso } \\
\text { compensá-lo. - Desligue velocidade de dobra. Parada total. - Sim, senhor. Parada total. - Segurem-se!. } \\
\text { Hipônimo de: dobra. Hiperônimo de: fator de dobra, fator } 1 \text {, fator } 2 \text {, impulso, sub luz. Córpus: Posição na } \\
\text { Ordem de Freqüência: (4); } N^{\circ} \text { de Ocorrências do termo: (127). Informações Enciclopédicas: A unidade } \\
\text { utilizada para velocidade de dobra é o factor de dobra. Os factores de equivalência obtidos por velocidades } \\
\text { de dobra pelo motor de dobra medidos em múltiplos da velocidade da luz é ambiguo. Em: Fator de dobra - } \\
\text { Memória Alfa }\end{array}$} \\
\hline & \\
\hline $\begin{array}{l}\text { Tipos de Consulta } \\
\text { Total } \\
\text { Tradutor } \\
\text { Modular }\end{array}$ & \\
\hline \multirow{4}{*}{$\begin{array}{l}\text { Consultas Externas } \\
\text { Corpus NILC } \\
\text { Google } \\
\text { Answers.com } \\
\text { Wikipedia } \\
\text { CORTEC }\end{array}$} & \\
\hline & $\boldsymbol{\nabla}$ English \\
\hline & Go back to search results \\
\hline & $\begin{array}{l}\text { Warp Speed. Star Trek. n.m/f.s. The rate at which a spaceship moves though space, measured by a warp } \\
\text { factor. Warp } 1 \text { equals the speed of light. Values below } 1 \text { indicate sublight speeds. Starting from warp 1, a } \\
\text { spaceship is able to move increasingly faster than light, according to its own warp capabilities.. Ex.: - Tell } \\
\text { them to get here as fast as they can. The Sh'Raan is capable of warp } 7 \text {. If we could maintain warp } 5 \text {, we'd } \\
\text { reach them in } 12 \text { minutes.. Hyponym of: warp. Hypernym of: warp factor, warp } 1 \text {, warp } 2 \text {, impulse, sublight. } \\
\text { Corpus: Frequency order position: (14); Term number of occurrencies: (83). Encyclopedic Information: Warp } \\
\text { factor, also known as time warp factor, was the primary means of measuring speeds attained using warp } \\
\text { drive. The term was often shortened to warp when followed by its value so that saying "warp six" is the same } \\
\text { as saying "warp factor six." Faster-tha em: Warp factor - Memory Alpha }\end{array}$ \\
\hline
\end{tabular}

Termo elaborado por Lucas Maciel Peixoto (pt)

Fonte: Elaborado por Lucas Maciel Peixoto

Já na figura três, encontramos no verbete baseado na série Teen Wolf, um etnotermo que remete totalmente ao folclore celta (e identificado no corpus como tal) sobre um ser sobrenatural; neste caso, o verbete foi elaborado por dois alunos.

Figura 3. Verbete Banshee

\begin{tabular}{|c|c|}
\hline Tipos de Exibição & $\boldsymbol{\nabla}$ Português \\
\hline Normal & \multirow{3}{*}{$\begin{array}{l}\text { Voltar ao resultado da busca } \\
\text { Banshee. TeenWolf. s.f.s. Banshees. Criatura metamorfa e perigosa, que não controla suas inspirações, prevê } \\
\text { mortes, encontra cadáveres, tem pressentimentos sobrenaturais e vozes na cabeça, não tem garras e nem } \\
\text { olhos brilhantes.. Ex.: - A Lydia é uma Banshee. Ela pode dizer quando alguém está para morrer.. Córpus: } \\
\text { Posição na Ordem de Freqüência: }(502) ; N^{\circ} \text { de Ocorrências do termo: (56). Informações Enciclopédicas: } \\
\text { Mulheres humanas especiais que têm o poder sobrenatural de sentir e prever quando alguém está prestes a } \\
\text { morrer. Em: Banshee - Wiki TeenWolf.serie }\end{array}$} \\
\hline Descritiva & \\
\hline $\begin{array}{l}\text { Tipos de Consulta } \\
\text { Total } \\
\text { Tradutor } \\
\text { Modular }\end{array}$ & \\
\hline \multirow{3}{*}{$\begin{array}{l}\text { Consultas Externas } \\
\text { Corpus NILC } \\
\text { Google } \\
\text { Answers.com } \\
\text { Wikipedia } \\
\text { CORTEC }\end{array}$} & $\boldsymbol{\nabla}$ English \\
\hline & Go back to search results \\
\hline & $\begin{array}{l}\text { Banshee. TeenWolf. n.m/f.s. A shapeshifter creature which can predict death or when someone's close to } \\
\text { die, and is also good at finding dead bodies.. Ex.: - That was the experimentation part. He did it to } \\
\text { Werewolves, Banshees, Wendigos, any creature he could get his hands on.. Hyponym of: Gaelic folklore. } \\
\text { Corpus: Frequency order position: (278); Term number of occurrencies: (55). Encyclopedic Information: } \\
\text { Banshees are special human women who have the supernatural power to sense and predict when someone is } \\
\text { about to die. em: Banshee - Teen Wolf Wiki }\end{array}$ \\
\hline
\end{tabular}

Termo elaborado por Marden Aleandro Rangel (pt) Joel Victor Reis Lisboa (en)

Fonte: Elaborado por Marden Aleandro Rangel e Joel Victor Reis Lisboa 
Pensando o projeto como um todo, posso afirmar que ele compartilha os pressupostos da Aprendizagem Direcionada por Dados (ADD; PEIXOTO, 2016), tudo que foi apresentado neste texto está relacionado à abordagem hard, onde os alunos devem descobrir, através do corpus, dados para que construam suas hipóteses ou produtos; nada impede, no entanto, o trabalho com uma abordagem soft, na qual o professor já apresente alguns dados do corpus prontos para o aluno (como as linhas de concordância dos etnotermos com os quais pretende trabalhar). Este projeto pode ser replicado, como um todo ou em partes, com alunos universitários, do ensino médio ou segunda metade do ensino fundamental, através das abordagens hard ou soft da ADD.

\section{Considerações finais}

Todo o caminho teórico e metodológico apresentado neste texto nos leva mais próximo a uma Terminografia Pedagógica. Demonstrei toda uma parte do que seria essa proposta: o aluno aprender a trabalhar com a Linguística de Corpus (compilação de corpus e seleção de etnotermos/etnofraseologismos através das suítes de análise lexical) e ambientes de gerenciamento terminográficos (como o VoTec) para criar o seu próprio verbete terminográfico (ainda que pertença a um seriado televisivo). Ser pedagógico, no caso, não é só trabalhar com ou criticar o produto (o que acontece muito com a literatura sobre Lexicografia Pedagógica), mas também saber escolher temas de interesse do público-alvo (no caso, os alunos) e investir no processo de aprendizagem desse público. Consumir um produto terminográfico pronto pode se mostrar como uma experiência incompleta para o aluno, já que terminologias fazem parte do nosso dia a dia: do Astronauta ao Zoólogo, do Artesão ao Zelador, todas as profissões têm terminologia própria; reconhecer que essas terminologias existem e saber elaborá-las é um passo importante para que os aprendizes possam reconhecê-las e valorizá-las.

Voltando ainda à questão dos produtos, concordo com vários autores que escrevem sobre Lexicografia Pedagógica (LP) e que criticam a elaboração das macroestruturas dos dicionários e as microestruturas de seus respectivos verbetes. Mas os produtos terminográficos parecem apresentar uma vantagem sobre os lexicográficos: a velocidade através da qual podemos mudar os ambientes de gestão e as páginas de visualização que trabalham com terminologias. Neste ponto, por exemplo, o ambiente VoTec está em constante evolução (já na versão 1.5) e foi adquirindo, com o passar do tempo, a característica de se tornar mais pedagógico, tendo em vista seus possíveis públicosalvo (aprendizes de alguma área de especialidade); novas funcionalidades, sugeridas por dissertações e teses de alunos e/ou pelos próprios alunos que trabalharam com o ambiente, foram sendo acrescidas ao banco de dados e página de visualização: etimologia, pronúncia da palavra, hyperlink para os termos já catalogados quando os 
mesmos aparecem em definições de outros verbetes, remissivas didáticas ${ }^{20}$ (como mostrado na figura $4^{21}$, já em outra versão do ambiente VoTec).

Figura 4. Verbete linguística

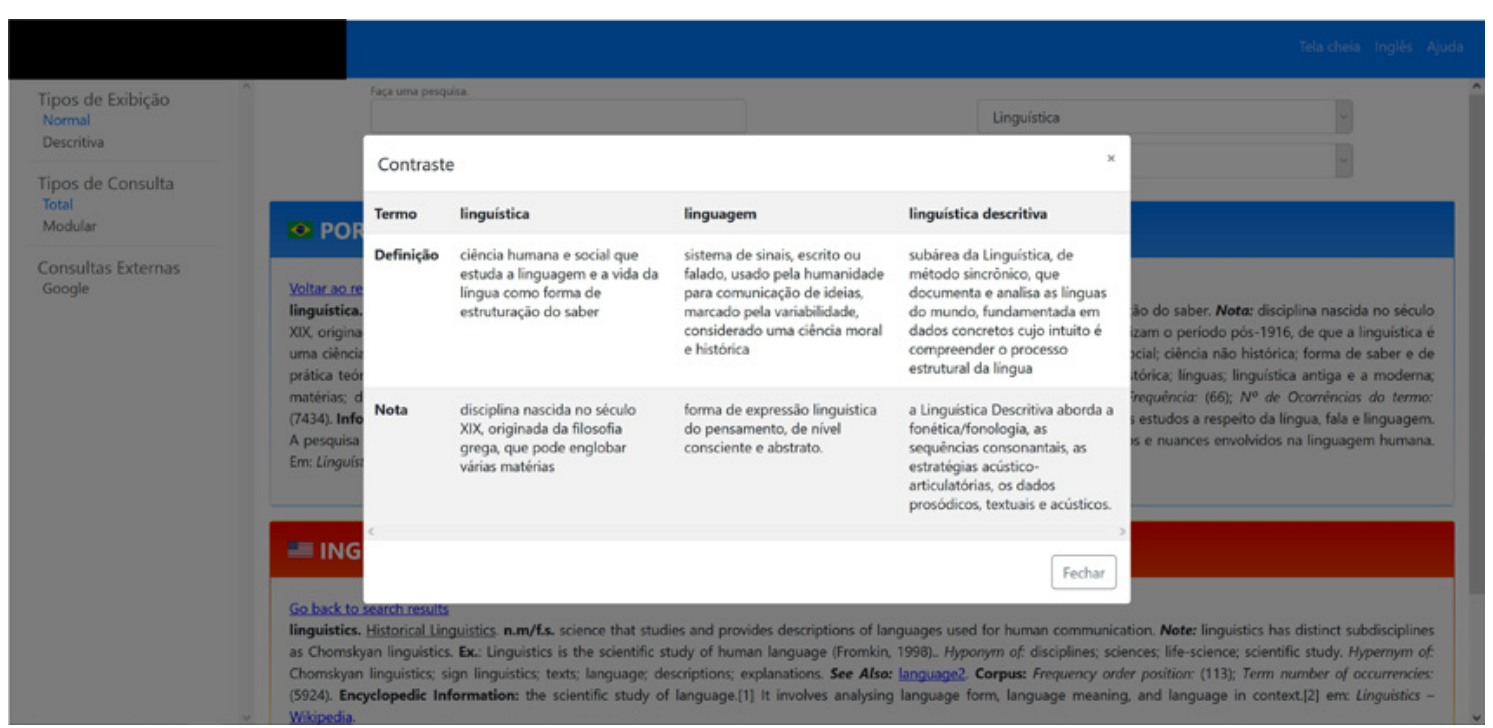

Fonte: Elaborado por Márcio Issamu Yamamoto

Minha proposta de Terminografia Pedagógica (TP) leva em consideração, portanto, alguns passos essenciais: a. ela deve ser baseada em corpus, com documentos (nos mais variados gêneros) disponíveis naquela área do conhecimento, a fim de apresentar exemplos reais no uso da língua de especialidade e proporcionar fundamentos para a elaboração de uma Árvore de Domínio dessa área, quando possível; b. inversamente à LP (predominantemente disponível em papel), o suporte básico da TP deve ser unicamente o digital (computadores, tablets, celulares ${ }^{22}$ ), podendo o vocabulário ser acessado a qualquer momento em qualquer plataforma e via Internet; c. ao contrário da LP, a TP não precisa de

20 Embora o ambiente sempre tenha apresentado a opção de criar remissivas em projetos mais robustos, notei que os consulentes raramente usavam essa funcionalidade na página de visualização. Para tentar melhorar o acesso e mostrar a importância de consultá-las, foi criada a remissiva pedagógica: ao invés do consulente ir até o verbete remissivo (que, por teoria, completa o sentido do termo que está sendo visualizado), basta passar o mouse sobre Veja Também (que nomeia a seção de remissivas) que um menu pop-up se abre e traz para o consulente uma tabela comparativa entre as definições do verbete que está consultando e aqueles disponíveis como remissivas.

21 Neste caso, o verbete visualizado é linguística. O menu pop-up mostrado apresenta este verbete, além dos dois que estão marcados como remissivas do mesmo, linguagem e linguística descritiva.

22 Celulares, por exemplo, podem ter páginas de visualização especialmente desenvolvidas para estes aparelhos. 
um "atravessador" como editoras - os frutos de pesquisa e desenvolvimento de produtos terminográficos podem e devem ser disponibilizados diretamente ao público-alvo final; d. assim como na LP, a TP deve pressupor uma análise cuidadosa do(s) público(s)-alvo final(ais), especialmente com dados advindos de pesquisas com esse público, pois é a partir dessa análise que o acesso à macroestrutura e a elaboração da microestrutura dos verbetes devem ser pensadas; e. o suporte digital deve pressupor uma constante evolução na disposição da macro-, média e microestruturas, logo deve ser refletido, desde sua concepção, como um sistema que necessitará de constantes atualizações.

\section{REFERÊNCIAS}

ALMEIDA, G. M. B.; CORREIA, M. Terminologia. 2008. Disponível em: http://www.letras. ufmg.br/gtlex/. Acesso em: 14 set. 2019.

BARBOSA, M. A. Dicionário, vocabulário, glossário: concepções. In: ALVES, I. M. (org.). A constituição da normalização terminológica no Brasil. 2. ed. São Paulo: FFLCH/CITRAT, 2001.

BARBOSA, M. A. Terminodidática: recortes epistemológicos e funções pedagógicas. Acta Semiotica et Lingvistica, João Pessoa, v. 14, n. 1, p. 58-71, 2009.

BARBOSA, M. A. Para uma etno-terminologia: recortes epistemológicos. Ciência e Cultura, São Paulo, v. 58, n. 2, p. 48-51, jun. 2006. Disponível em: https://bit.ly/2MnsNgC. Acesso em: 14 set. 2019.

BARBOSA, M. A. A terminologia e o ensino da metalinguagem técnico-científica. In: ISQUERDO, A. N.; KRIEGER, M. da G. (org.). As ciências do léxico: lexicologia, lexicografia, terminologia. v. II. Campo Grande: Ed. UFMS, 2004.

BERBER SARDINHA, A. Lingüística de corpus. Barueri: Manole, 2004.

BRASIL. Ministério da Educação. Secretaria de Educação Básica. Com direito à palavra: dicionários em sala de aula. Brasília: Ministério da Educação, Secretaria de Educação Básica, 2012.

CABRÉ, M. T. Hacia una teoría comunicativa de la terminología: aspectos metodológicos. In: CABRÉ, M. T. La Terminologia: representación y comunicación. Barcelona: IULA, 2000. p. 129-150. 
CABRÉ, M. T.; ESTOPÀ, R.; FREIXA, J. Lengua y léxico. In: ESTOPÀ, R. (coord.). Hablamos de lengua con niños y niñas. Barcelona: Editorial Graó, 2006.

CARNEIRO, R. M. O. Discurso literário de fantasia infantojuvenil: proposta de descrição terminológica direcionada por corpus. 2016. Dissertação (Mestrado em Estudos Linguísticos) - Universidade Federal de Uberlândia, Uberlândia, 2016. Disponível em: https://repositorio.ufu.br/handle/123456789/18082. Acesso em: 14 set. 2019.

DARÉ-VARGAS, M. Lexicografia Pedagógica. Domínios de Lingu@gem, v. 12, n. 4, p. 19341949, jan. 2019. DOI: https://doi.org/10.14393/DL36-v12n4a2018-2. Acesso em: 14 set. 2019.

FINATTO, M. J. B. A experiência de elaboração do dicionário de Linguística da Enunciação. In: ISQUERDO, A. N.; BARROS, L. A. (org.). As ciências do léxico: lexicologia, lexicografia, terminologia. v. V. Campo Grande: Ed. UFMS, 2010.

FROMM, G. Proposta para um modelo de glossário de informática para tradutores. 2002. Dissertação (Mestrado em Semiótica e Linguística Geral) - Faculdade de Filosofia, Letras e Ciências Humanas, Universidade de São Paulo, São Paulo, 2002.

FROMM, G. VoTec: a construção de vocabulários eletrônicos para aprendizes de tradução. 2007. Tese (Doutorado em Estudos Linguísticos e Literários em Inglês) Faculdade de Filosofia, Letras e Ciências Humanas, Universidade de São Paulo, São Paulo, 2007.

FROMM, G. Ficção, Tradução, Terminografia e Linguística de Corpus: confluências. In: XIII Simpósio Nacional de Letras e Linguística e III Simpósio Internacional de Letras e Linguística, 2011, Uberlândia. Anais do SILEL, Uberlândia, v. 2, n. 2, EDUFU, 2011.

HOUAISS, A. Houaiss eletrônico. Objetiva, 2009.

ILARI, R. Introdução ao estudo do léxico - brincando com as palavras. 2. ed. São Paulo: Contexto, 2003.

LAFACE, A. Definição de vocabulário terminológico no universo acadêmico: reflexões didático-pedagógicas. In: OLIVEIRA, A. M. P. P. de; ISQUERDO, A. N. (org.). As ciências do léxico: lexicologia, lexicografia, terminologia. 2. ed. Campo Grande: Ed. UFMS, 2001. 
KRIEGER, M. G.; FINATTO, M. J. B. Introdução à terminologia: teoria e prática. São Paulo: Contexto, 2004.

OLIVEIRA, A. M. P. P. de; ISQUERDO, A. N. (org.). As ciências do léxico: lexicologia, lexicografia, terminologia. 2. ed. Campo Grande: Ed. UFMS, 2001.

PEIXOTO, L. M. O Corpus of English Language Videos: uma nova ferramenta de corpus on-line para aprendizagem direcionada por dados. 2016. Dissertação (Mestrado em Estudos Linguísticos) - Universidade Federal de Uberlândia, Uberlândia, 2016. Disponível em: https://repositorio.ufu.br/handle/123456789/18315. Acesso em: 15 set. 2019.

TAGNIN, S. E. O. Corpora: o que são e para que servem. Minicurso. São Paulo, 2004. Disponível em: http://comet.fflch.usp.br/sites/comet.fflch.usp.br/files/u30/ Lexicografia_2004.pdf. Acesso em: 14 set. 2019.

TAGNIN, S. E. O. Glossário de Linguística de Corpus. In: TAGNIN, S. E. O.; VIANA, V. (org.). Corpora no ensino de línguas estrangeiras. São Paulo: Hub Editorial, 2010.

TEIXEIRA, E. D. A lingüística de corpus a serviço do tradutor: proposta de um dicionário de culinária voltado para a produção textual. 2008. Tese (Doutorado em Estudos Linguísticos e Literários em Inglês) - Faculdade de Filosofia, Letras e Ciências Humanas, Universidade de São Paulo, São Paulo, 2008. DOl:10.11606/T.8.2008.tde-16022009141747. Acesso em: 14 set. 2019.

WILKENS, R. et alii. Ambientes web de gestão terminológica para criação de produtos terminológicos online. Debate Terminológico, n. 8, p. 16-22, jun. 2012. Disponível em: http://seer.ufrgs.br/index.php/riterm/article/view/29877/18474. Acesso em: 31 jan. 2014.

ZAVAGLIA, C.; WELKER, H. Lexicologia. 2008. Disponível em: http://www.letras.ufmg.br/ gtlex/. Acesso em: 14 set. 2019. 